\title{
Predictors of food insecurity and coping strategies of women asylum seekers and refugees in Durban, South Africa
}

\author{
Carin Napier ${ }^{1 *} \mathbb{C}$, Wilna Oldewage-Theron ${ }^{2}$ and Beryl Makhaye
}

\begin{abstract}
Background: This cross-sectional study assessed the prevalence of household food insecurity and the association between food insecurity and coping strategies among women asylum seekers and refugees in the city of Durban in South Africa.

Methods: A coping strategy questionnaire was used to determine food security as this gives a good indication of what the women have to go through in order to provide safe and nutritionally sound meals to family members. The questionnaire also presents an indicator of food security, with a higher score indicating a higher level of food insecurity. Participants were recruited in the Durban city centre from church and community meetings and in their workplace. Data were collected from 200 women. Households were classified as food-secure and food-insecure groups for comparison purposes. Data were analysed on SPSS, version 23.0, for descriptive statistics, correlations, and logistic and bivariate linear regression.
\end{abstract}

Results: The results showed that $96.2 \%$ of the women were living in poverty ( $<$ US\$1.9 per person per day). Only $8.0 \%$ of the women were food secure. Regarding the coping strategies, except for'sending children to the refugee preschools' the number of coping strategies was significantly higher in the food-insecure group $(p=0.000)$. The number of people in the household, the unemployment status of the women and household income were predictors of poverty $\left(R^{2}=0.859, p=0.000, S E E=0.189\right)$. Larger household size, households spending between ZAR700 and ZAR900 on food monthly (OR 1.01; $\mathrm{Cl} 0.26-4.56$ ) and households purchasing food from street vendors (OR 4.02; $\mathrm{Cl} 01.35-46.23$ ) or informal community shops (OR 4.1; Cl 0.42-40.22) were indicators of food insecurity.

Conclusion: This study points to a serious problem of household food insecurity among black women asylum seekers and refugees in the city of Durban, South Africa. The food security status of this group of women can possibly impact on the nutritional status of the family unit and make the family vulnerable to disease and illness. This will place an additional burden on the government in providing healthcare services to refugees and asylum seekers.

Keywords: Food insecurity, Refugee, Households, Women, Coping strategies

\section{Background}

Since 1994, South Africa has become a popular destination for asylum seeker and refugees, especially those from other African countries [14]. According to the United Nations High Commissioner for Refugees UNHCR [29], South Africa (SA) currently hosts 1,096,063 asylum

\footnotetext{
*Correspondence: carinn@dut.ac.za

${ }^{1}$ Department of Food and Nutrition Consumer Sciences, Durban University of Technology, P. O. Box 1334, Durban 4000, South Africa Full list of author information is available at the end of the article
}

seekers and 121,645 refugees. The Geneva Convention defines an asylum seeker as a person who crosses international borders out of fear of being persecuted for belonging to a specific group or ideology, race, religion or gender. These people seek protection in a foreign country because the country of origin is not willing to protect them or is the cause of violation of human rights. They need to apply to the host country to be registered as refugees. A refugee is defined as a person who has wellfounded fears of being persecuted for a variety of reasons

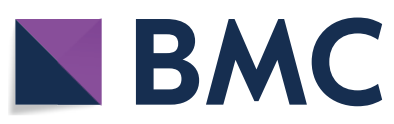

(c) The Author(s) 2018. This article is distributed under the terms of the Creative Commons Attribution 4.0 International License (http://creativecommons.org/licenses/by/4.0/), which permits unrestricted use, distribution, and reproduction in any medium, provided you give appropriate credit to the original author(s) and the source, provide a link to the Creative Commons license, and indicate if changes were made. The Creative Commons Public Domain Dedication waiver (http://creativecommons.org/ publicdomain/zero/1.0/) applies to the data made available in this article, unless otherwise stated. 
including their political or religious affiliation, having a specific racial or social profile, or who has experienced persecution or been unfairly prejudiced because of their gender or sexual orientation. The term 'refugee' refers to someone who has been processed and registered with the (South African) Department of Home Affairs as a refugee UNHCR [28].

Annual reports of UNHCR in South Africa indicate that asylum seekers and refugees are mainly urban city dwellers; therefore, promotion of self-reliance is crucial to prevent dependency. As of 2012, when this study was undertaken, the UNHCR regional office through its implementing partners in various provinces such as Refugee Social Services in KwaZulu-Natal, Jesuit Refugee Services in Gauteng and the Cape Town Refugee Centre has assisted 6000 refugee children with basic education and 20,000 refugee learners with education support material. Furthermore, vocational training was offered to 10,000 adult refugees and English classes were made available to 20,000 recipients to empower refugees and asylum seekers with skills to access the labour market UNHCR [27].

The most vulnerable groups which include children, women with children, the elderly, and disabled asylum seekers and refugees are provided with material assistance such as food, shelter and medical referral for a period of 3 months. Thereafter, implementing partners, such as the Consortium for Refugees and Migrants in South Africa (CoRMSA) and the Department of Social Development, need to facilitate access to local charitable organisations and state structures for grants. The majority of asylum seekers and refugees in Africa are women and children, and they are the most vulnerable groups in a population. These women have to cope with a variety of challenges while settling into the new camp or host country [10]. Not only do they have to adjust to a new culture and language, and more often than not xenophobia and crime situations, but they also have to provide for their children and often have to cope with unfamiliar food choices and limited resources [6, 10, 14]. Access to healthy foods, specifically in urban areas where most asylum seeker and refugees are based, is often difficult and depends on many factors such as distance to shops and access to transport, availability of affordable quality foods and lack of nutrition knowledge [4, 7, 8]. A large number of asylum seekers and refugees in South Africa thus survive through personal networks and family support. Women with children often approach faith-based organisations (FBO) and local non-governmental organisations (NGOs) for food and other material assistance (African Centre for Migration and Society (ACMS) [1]. There is a paucity of information about the food security status of refugee families; however, the few studies available showed a high prevalence of food insecurity, hunger and malnutrition among asylum seeker and refugees. Poverty and food insecurity, leading to low food accessibility and poor dietary quality, can thus have a detrimental effect on their health and quality of life $[6,14]$.

Although a study of this limited literature has demonstrated the high prevalence of food insecurity and its effect on asylum seeker and refugees, little is known about how women asylum seekers and refugees cope with food insecurity and their living conditions. Furthermore, socio-economic factors are important indicators of health, food and nutrition security [2]. In an effort to address this gap in the literature, this study had several aims, namely to (a) determine the prevalence and severity of food insecurity; (b) examine the use of various coping strategies used by the food-insecure refugees, (c) describe the relationship between socio-economic factors and food insecurity and (d) describe the socio-economic predictors of food insecurity among women asylum seekers and refugees in Wards 26 and 28 in the city of Durban.

\section{Methods}

A mixed-methods design was used. A sample size calculator (The Survey System) was used to calculate a statistically representative sample. Female asylum seekers and refugees were recruited after church and community meetings as well as during or after their shift work as car guards in Durban CBD and were selected using targeted sampling until the sample size of 200 women was obtained. Women were selected to participate in the study if they met the following criteria: (a) being in possession of Section 22 or 24 documents from the Department of Home Affairs for asylum seekers or refugees, respectively, (b) aged 19-50 years of age, (c) living in Ward 26 area (North and South Beach) and Ward 28 area (Central Business District-CBD) in the city of Durban, and (d) conversant in English and Swahili. Each participant was informed about the study before implementation. Participation was voluntary, and informed consent was obtained from all participants included in the study. The women were informed that they could withdraw from the study at any time without being penalised. Furthermore, the participants received food parcels on completion of the interview, but had not been informed that they would receive the food parcels on recruitment. Receiving the food parcels would thus not have affected their decision to participate in the study.

Trained final-year Food and Nutrition students from Durban University of Technology (DUT) acted as fieldworkers to collect data from the study participants. Fieldwork was conducted between February and August 2013. All the questionnaires were translated into Swahili and either administered in English or Swahili, based on the participant's preference, by trained fieldworkers in a 
one-on-one interview situation. The Swahili questionnaire was translated back into English by another person to ensure conceptual agreement. Each interview lasted for approximately $30 \mathrm{~min}$. A valid and reliable sociodemographic questionnaire was used [18] to collect sociodemographic data and determine the socio-economic profile of the women. A number of independent variables such as age, marital status, employment status, accommodation arrangements, household composition, education level, household income and food procurement and consumption patterns were included in the questionnaire.

The validated coping strategy questionnaire developed by Maxwell et al. [16] was adjusted in a focus group discussion with 10 women from the refugee community, who were not included in the main study, to determine which coping strategies, as listed in the questionnaire but supplemented with others as suggested by the women, should be used to address food and nutrition insecurity in the refugee community. These coping strategies were listed, and the same women ranked the severity of each of the coping strategies during the focus group discussion from one (least severe) to four (most severe) as described by Maxwell et al. [16]. The additional coping strategies identified by the women that were included were: 'Rely on food aid from Non-Governmental Organizations and Faith Based Organizations' and 'Send young children in the household to be fed at the local refugee pre-school' and these were both ranked as a four severity weight. This list of coping strategies with their severity rankings became the coping strategy questionnaire administered to the women. This was not pre-tested and internal validity was thus not determined. The women had to report their experience of food security for the preceding onemonth period [17]. The questionnaire included the following nine coping strategies: skipping meals for an entire day, reducing the number of meals per day, relying on aid from a local NGO/FBO, relying on the community or friends for food, buying less preferred and less expensive foods, restricting the amount of food consumed by adult women, feeding the employed man of the household first, sending children to eat at a local refugee preschool and limiting portion sizes at meal times.

\section{Statistical analysis}

The socio-demographic questionnaires were captured on a Microsoft Excel spreadsheet and analysed on the Statistical Package for the Social Sciences (SPSS) software version 23 for descriptive statistics (frequencies for categorical data, means and standard deviations [SDs] for numerical data) presented in graphs and tables. The coping strategy questionnaires were captured on a Microsoft Excel spreadsheet and analysed. Frequencies for each of the coping strategies were calculated. The mean \pm SD coping strategies index
(CSI) was calculated. The CSI was chosen for this study as it measures food consumption behaviour when the respondents cannot access enough food and was adopted by many agencies such as the World Food Programme Vulnerability Analysis Mapping unit, the United Nations Food and Agriculture Organization and the Global Integrated Phase Classification team, among others, to use as an indicator to measure food security [31]. It was also found that the CSI and the Household Food Insecurity Access Scale (HFIAS) corroborated the full set of food security measures focusing on consumption behaviours including CSI, reduced coping strategy index (rCSI), HFIAS, household dietary diversity score, food consumption score (FCS), self-assessed measure of food security (SAFS) more than the others [17]. The CSI does not have universal cut-off points for different categories of insecurity [17], and the researchers used the classification of food security based on other studies undertaken to classify the women as food secure or food insecure as follows: food secure (CSI 0-2), mildly food insecure (CSI 3-12), moderately food insecure (13-40) and severely food insecure (CSI >40) [17]. The sample was further classified as food secure (including mildly food secure) and food insecure (including moderately and severely food insecure) for comparison between food-secure and food-insecure groups. Analysis of variance (ANOVA) with the correction of Bartlett's test for equal variances at a significance level of $p \leq 0.05$ was used to determine significant differences for the numerical data between the groups. Nonparametric hypothesis test summaries were performed for categorical socio-economic data to determine significant differences between the groups.

Pearson and Spearman correlations were used to determine significant relationships between numerical and categorical variables, respectively. Only significant relationships are reported in the results. Bivariate linear regression analysis for predictors of poverty $(<$ US $\$ 1.9$ per person per day cut-off-The World Bank [25]) was also employed to identify socio-economic factors that could explain the existing poverty and food insecurity status among this group of women asylum seekers and refugees. A logistic regression analysis was used to estimate socioeconomic and demographic variables contributing to food insecurity. Those variables with significant correlations as determined by the Pearson and Spearman correlations were included in the logistic regression analyses. The results from the logistic regression model are stated as odd ratios with $95 \%$ confidence intervals.

\section{Results \\ Respondent characteristics}

The mean age $\pm S D$ of the participants was $38.5 \pm 7.8$ years. The sample was exclusively black women 
who spoke mainly Burundi (31.0\%) and Swahili (28.0\%). The average household size was $6.9 \pm 2.8$ persons and ranged from $2(4.0 \%)$ to $11(26.5 \%)$ people. The majority $(82.5 \%)$ of the women had been living in South Africa for less than 5 years. The majority of women lived in a rented apartment (71.5\%), followed by $25.0 \%$ who lived in hostel accommodation. The women had a relatively high literacy rate as $49.0 \%$ had completed secondary school, and $23.0 \%$ had a college qualification and $4.5 \%$ had a post-school qualification. Although $36.5 \%$ of the women were employed, the mean $\pm S D$ monthly household income was ZAR1656.99 \pm 956.97 . A large percentage (96.2\%) of the women were living in poverty according to the $<$ US $\$ 1.9$ per person per day cut-off (The World Bank [25]), and $91.3 \%$ and $96.0 \%$, respectively, were living in poverty according to the KwaZulu-Natal lowerbound poverty line (LBPL) of ZAR539 and upper-bound poverty line (UBPL) of ZAR757 (Statistics South Africa (Stats SA) [24]). In 39.0\% of the households, the woman was a mother and the head of the household. In the majority of the households, the women were responsible for food preparation (98.5\%) and feeding the children (90.8\%), as well as making decisions about the amount of money spent on food (65.8\%) and the type of food to buy (86.5\%). The mean \pm SD spent on food per month was ZAR789.53 \pm 432.13 and contributed $60.3 \%$ of the total income. Food was mainly bought from the informal food vendors in the residential area (93.0\%) weekly (56.0\%) by the majority of households, followed by daily (25.5\%) and monthly (18.5\%). Most of the meals (92.9\%) are consumed at home and the majority of the women consumed only one meal per day (55.5\%), followed by $34.5 \%$ and $1.5 \%$ consuming two or three meals, respectively, with $8.5 \%$ who had not consumed any meals the day before data collection. The majority of the women $(68.3 \%)$ indicated that they sometimes experienced a food shortage, whereas $18.6 \%$ and $9.5 \%$ indicated that they often and always experienced not having enough money to buy food, respectively. All the women had potable water and sanitation facilities available in the house; however, they had a problem with cockroaches $(86.0 \%)$ and mice $(44.0 \%)$ and ants $(37.5 \%)$ in the house. Although they all had electricity available, only $3.5 \%$ used electricity for food preparation. Wood fires (93.5\%) were mainly used for food preparation.

The results in Table 1 show a comparison between the socio-demographic characteristics of the food-secure and food-insecure households. No significant differences were observed in socio-economic variables between the food-secure and food-insecure groups. However, the food-insecure group experienced a shortage of money to buy food often or always in $36.3 \%$ of the households compared to $22.0 \%$ in the food-secure households $(p<0.05)$. The latter indicates that although the women were classified as food secure by the CSI, $4.6 \%$ and $17.4 \%$ of the women in the food-secure group indicated that they always and often did not have enough money to buy food, respectively, thus having to employ coping strategies such as relying on the community or family to provide them with food.

\section{Prevalence of food insecurity}

The mean \pm SD household CSI was $50.6 \pm 34.8$ and ranged from 0.0 to 171.0 . Only $8.0 \%$ of the women were food secure compared to $46.5 \%, 45.0 \%$ and $0.5 \%$ who were mildly, moderately and severely food insecure, respectively [16] (Fig. 1).

The results in Fig. 2 show that all the coping strategies identified by the respondents were used by the majority of the households, except for sending young children to eat at the local refugee pre-school (45.0\%). The three most used coping strategies were: reducing the number of meals of all the adult women in the house (92.5.0\%), buying less preferred and expensive foods (90.0\%) and limiting portion sizes at meals (83.5\%) (Fig. 2).

All the coping strategies were applied significantly $(p=0.000)$ more in the food-insecure groups than in the food-secure group, except for sending out the children to eat at the refugee pre-school for which no significant difference $(p=0.083)$ between the groups was observed. More than $90 \%$ of the women in the moderately and severely insecure group employed coping strategies with 98.9\% skipping meals for an entire day, $100.0 \%$ reduced the number of meals eaten in a day, $100.0 \%$ relied on less preferred and more affordable foods, 93.4\% restricted food consumption for themselves and $98.9 \%$ limited portion sizes at meals (Fig. 3). The coping strategies most employed by the food-secure group included a reduced number of meals per day $(86.2 \%)$ and relying on less preferred and expensive foods (81.7\%).

A significant positive relationship was observed between CSI (food security/insecurity indicator) and being unemployed $(r=0.157 ; p=0.012)$ at the 0.001 level (99\% confidence level), and a significant adverse relationship with money spent on food $(r=-0.130$; $p=0.021)$ and not enough food in the household $(r=-0.162 ; p=0.004)$ was also observed. Furthermore, significant relationships were found between the available household US\$ per person per day (proxy for poverty) and the variables measured in this study (Table 2).

The logistic regression analysis carried out on the socio-economic and demographic predictors of poverty (\$ per person per day) showed that the number of people 


\begin{tabular}{|c|c|c|}
\hline Variable & $\begin{array}{l}\text { Food secure, } n=109 \\
(54.5 \%)\end{array}$ & $\begin{array}{l}\text { Food insecure, } n=91 \\
(45.5 \%)\end{array}$ \\
\hline \multicolumn{3}{|c|}{ Number of household members } \\
\hline $1-3$ & $12(11.0)$ & $9(9.9)$ \\
\hline $4-6$ & $45(41.3)$ & $37(40.7)$ \\
\hline $7-11$ & $52(47.7)$ & $45(49.4)$ \\
\hline \multicolumn{3}{|c|}{ Current employment status } \\
\hline Employed & $34(31.2)$ & $39(42.9)$ \\
\hline Unemployed & $75(68.8)$ & $52(57.1)$ \\
\hline \multicolumn{3}{|l|}{ Education status } \\
\hline $\begin{array}{l}\text { No schooling or up } \\
\text { to primary school }\end{array}$ & $9(8.2)$ & $7(7.7)$ \\
\hline Standard 8 & $18(16.5)$ & $13(14.3)$ \\
\hline Standard 10 & $57(52.3)$ & $41(45.0)$ \\
\hline $\begin{array}{l}\text { College/FET or com- } \\
\text { pleted post-school }\end{array}$ & $25(23.0)$ & $30(33.0)$ \\
\hline \multicolumn{3}{|c|}{ Do not have enough money to buy food* } \\
\hline Always & $5(4.6)$ & $14(15.4)$ \\
\hline Often & $19(17.4)$ & $19(20.9)$ \\
\hline Sometimes & $81(74.3)$ & $55(60.4)$ \\
\hline Seldom or never & $4(3.7)$ & $3(3.3)$ \\
\hline \multicolumn{3}{|c|}{ Types of places or shops for purchasing food } \\
\hline Supermarket & $100(91.7)$ & $81(89.0)$ \\
\hline Wholesalers & $3(2.8)$ & $2(2.2)$ \\
\hline Street vendor & $2(1.8)$ & $3(3.3)$ \\
\hline $\begin{array}{l}\text { Informal community } \\
\text { shop }\end{array}$ & $4(3.7)$ & $5(5.5)$ \\
\hline Variable & $\begin{array}{l}\text { Food secure, } n=72 \\
\text { (\%) }\end{array}$ & $\begin{array}{l}\text { Food insecure, } n=60 \\
(\%)\end{array}$ \\
\hline \multicolumn{3}{|c|}{ Household monthly income } \\
\hline $500-1000$ & $16(22.2)$ & $9(15.0)$ \\
\hline $1001-1500$ & $22(30.6)$ & $16(26.7)$ \\
\hline $1501-2000$ & $12(16.7)$ & $11(18.3)$ \\
\hline $2001-2500$ & $10(13.9)$ & $9(15.0)$ \\
\hline $2501-\geq 3000$ & $12(16.7)$ & $15(25.0)$ \\
\hline \multicolumn{3}{|c|}{ Money spent on food on monthly basis } \\
\hline $100-300$ & $8(11.1)$ & $6(10.0)$ \\
\hline $301-500$ & $10(13.9)$ & $8(13.3)$ \\
\hline $501-700$ & $27(37.5)$ & $18(30.0)$ \\
\hline $701-900$ & $16(22.2)$ & $15(25.0)$ \\
\hline $901-\geq 1500$ & $11(15.3)$ & $13(21.7)$ \\
\hline
\end{tabular}

${ }^{*} p<0.05$

in the house, unemployment status of the woman and household income were predictors of poverty $\left(R^{2}=0.843\right.$, $p=0.000$, SEE $=0.189$ ). The binomial and multinomial regression analyses showed no significant socio-economic and demographic predictors of food insecurity.

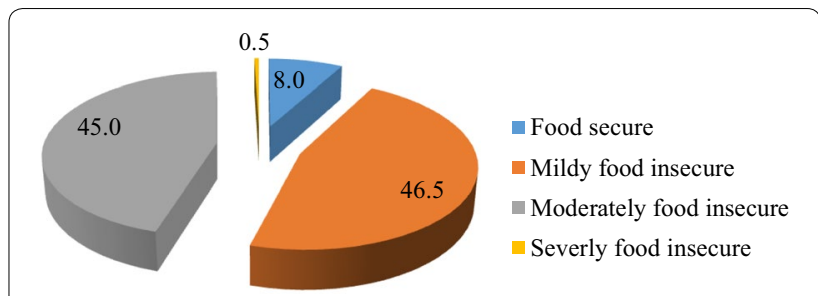

Fig. 1 Household food insecurity status $(n=200)$

\section{Discussion}

South Africa has become a popular destination for refugees from other African nations [14]. Although South Africa is viewed as food secure at the country level [14], it is estimated that $26.6 \%$ of households are food insecure [23]. Little information is available about the food insecurity situation among refugees in South Africa, and the objective of this research was thus to contribute an understanding of the extent of food insecurity and to investigate the coping strategies and socio-economic predictors of food insecurity of women asylum seekers and refugees in Durban.

Despite the considerable progress in the political and economic status since 1994, poverty and unemployment are still major challenges faced by many people in the country [13], especially refugees who have to compete with South African citizens for the already scarce resources, and are often faced with difficult circumstances. The monthly household income of these women was ZAR1657, which was slightly more than the estimated average income of the poor in South Africa [13]. However, almost all the women in this study lived in poverty $(<1.9$ US\$ per person per day-The World Bank [25]) and only about a third were employed despite having a relatively high literacy rate. It was thus not surprising that there was no statistically significant difference between the incomes of the food-secure and food-insecure households.

As expected, the prevalence of food insecurity among these women asylum seekers and refugees was very high (92\%), which is much higher than the national prevalence of $26.6 \%$ food insecurity and $28.3 \%$ at risk of hunger [23]. These results are consistent with studies conducted among refugees from Liberia, West Africa and Somali in the USA $[6,11,12]$. Of the food insecure in this study, $46.5 \%$ of the women were categorised as mildly food insecure, $45.0 \%$ as moderately food insecure and $0.5 \%$ as severely food insecure. Food insecurity usually occurs when people do not have access or money to purchase 


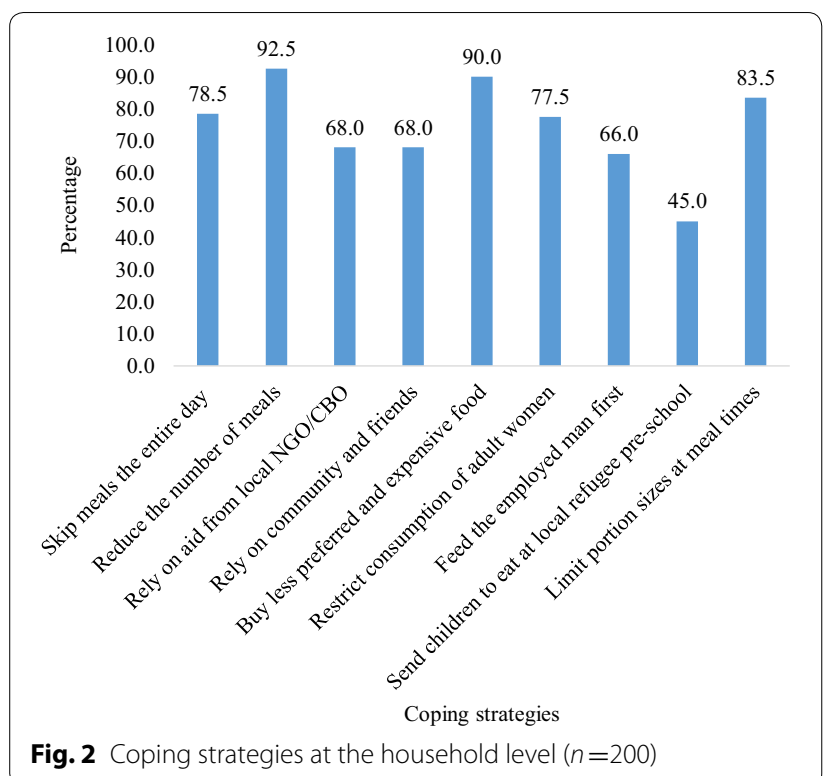

food at all times [5, 21]. Food-insecure households are often at risk of food shortages $[15,19,22]$. In this study, $60.3 \%$ of the total household income was spent on food and the majority of the women indicated that they sometimes $(68.3 \%)$, often $(18.6 \%)$ or always $(9.5 \%)$ experienced a food shortage, resulting in the majority of the women only consuming one meal per day. Furthermore, food shortages in the household led to the adoption of coping strategies that could adversely impact the household's food security situation in the short and long term [15, $19,22]$. Coping strategies were also adopted by this refugee community. Common household responses to food shortages include reduced food intakes, changes in types of foods served and adjusting the food budget [21]. These responses were also found in this study as the two coping strategies used by more than $90 \%$ of the women included reducing the number of meals and buying less preferred and less expensive foods. The aforementioned was also consistent with the finding that the majority of women indicated that they consumed only one meal a day. More than $75 \%$ indicated that they would limit portion sizes, restrict the consumption of the adults and go without food a whole day. The latter response was also found in this study in that $8.5 \%$ of the women indicated that they had not eaten the whole day before the survey was undertaken. More than $60 \%$ of the women relied on the community, friends and local NGOs for food. This is consistent with the findings from another study where refugees in Kenya reported that the informal social support from family, friends and others in the community was an important coping strategy [10]. All the coping strategies
Limit portion sizes at meal times

Send primary school children to be fed at local pre-school for meals after school

Feed working members of the household at the expense of other family members

Restrict consumption for a women/mother

Rely on less preferred and less expensive foods

Rely on help fom community-based network and friends

Rely on food aid from NGOs and CBOs

Reduce the number of meals eaten in a day

Skip the entire day without eating

98.9

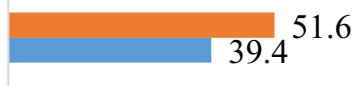

70.6
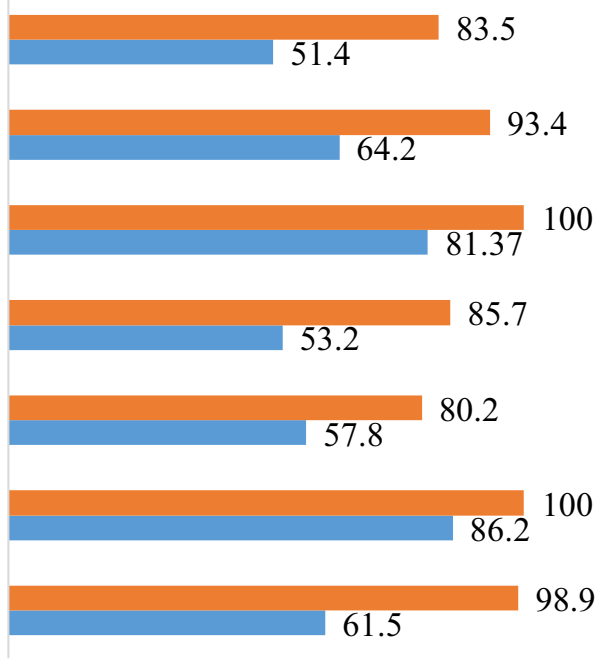

$\begin{array}{lllllll}0 & 20 & 40 & 60 & 80 & 100 & 120\end{array}$

Food insecure Food secure

Fig. 3 Comparison of coping strategies between the food-secure and food-insecure groups $(n=200)$ 
Table 2 Significant correlations between the CSI and the amount of money available per person per day and various variables

\begin{tabular}{lcl}
\hline Variables & Correlation $\boldsymbol{r}$ & Significance $\boldsymbol{p}$ \\
\hline US\$ per person per day (poverty indicator) with & \\
Number of people in house & -0.525 & 0.000 \\
Total income & 0.605 & 0.000 \\
Money spent on food per month & 0.321 & 0.000 \\
Unemployment & -0.185 & 0.007 \\
Frequency of purchasing food & 0.168 & 0.010 \\
Not enough food in the house & 0.281 & 0.000 \\
Education & 0.159 & 0.012 \\
Mother as head of the household & -0.143 & 0.031 \\
Number of meals per day & 0.172 & 0.004 \\
Food insecurity (CSI) with & & \\
Not enough food in the house & -0.162 & 0.004 \\
Money spent on food & -0.130 & 0.021 \\
Unemployment & 0.157 & 0.012 \\
\hline
\end{tabular}

were applied significantly $(p=0.000)$ more in the foodinsecure group than in the food-secure group, except for sending the children out to eat at the refugee pre-schools for which no significant difference $(p=0.083)$ between the groups was observed. This finding suggests that the food-insecure women managed their food insecurity by significantly utilising coping strategies more frequently than their food-secure counterparts. A study in Kenya has found that the primary concerns of women refugees were mainly focused on their daily needs for food and shelter [10].

In examining the relationship of food insecurity to socio-economic variables, a significant positive relationship was observed between the CSI (as a proxy for food insecurity) and being unemployed, as well as a significant adverse relationship with available money to spend on food. Food access is thus severely compromised by unemployment and a lack of financial resources in this refugee community. Although these two factors were not found to be predictors of food insecurity, both unemployment and household income were predictors of poverty in this community. Although poverty has been identified as a risk factor for food insecurity [6], no significant relationship between poverty and food insecurity was found in this study.

A limitation of this study is the small sample size. The targeted sampling strategy may have introduced a selection bias, and it is thus not representative of all women asylum seekers and refugees in Durban. Another limitation may be that different measures were used to determine food security (10-item Radimer/Cornell hunger scale, HFIAS and CSI) in the various studies used in comparing our results. However, all these measures included coping strategies and, as previously mentioned, the CSI corroborates well with HFIAS among others $[17,20]$. The coping strategies questionnaire used for this study was based on focus group results and was not pre-tested; thus, the internal consistency of the scale was not tested. Our findings can thus not be generalised to the larger refugee population in South Africa and may reflect on only those women asylum seekers and refugees who attend church and community meetings, and those that work as car guards in the Durban CBD. The results, however, represent a good first attempt at understanding household food insecurity and the coping strategies adopted to cope with this among women refugees and asylum seekers in South Africa. The results further highlight the need for more research among women refugees and asylum seekers, especially on the impact of food insecurity on health and nutritional status.

\section{Conclusions}

It was difficult to compare our results across other similar studies because of the paucity of data on the extent of food insecurity and coping strategies among refugees in South Africa. However, this study points to a serious problem of household food insecurity among black women asylum seekers and refugees. This is also true for the USA [6]. Larger households were associated with both poverty and food insecurity in this group of women. Poverty and food insecurity have both been identified as predictors of nutritional outcomes among adults [3]. Specifically, food insecurity has a detrimental effect on nutritional and health status as a number of studies have found that food insecurity is associated with poor dietary intake because of limited economic resources $[5,26,30]$. Food security refers to both adequate nourishment (intake) and adequate nutrition (quality of diet and utilisation) [9]. In this study, a number of coping strategies were employed that could adversely affect dietary intake and nutritional status. More research is thus needed to investigate how food insecurity affects the food choices and dietary intake as well as nutritional status of these women refugees and asylum seekers. More longitudinal research in South Africa and/or sub-Saharan Africa is also needed to explore the various socio-demographic variables that contribute to food and nutrition insecurity among refugees in order to plan and implement appropriate strategies to address food and nutrition insecurity effectively and efficiently among this group of vulnerable people.

\section{Abbreviations}

UNHCR: United Nations High Commission for Refugees; SA: South Africa; CORMSA: Consortium for Refugees and Migrants in South Africa; FBO: 
Faith-based organisations; NGOs: Non-governmental organisations; ACMS: African Centre for Migration and Society; CBD: Central Business District; DUT: Durban University of Technology; SPSS: Statistical Package for Social Sciences; SDs: Standard deviations; CSI: Coping strategy index; HFIS: Household Food Insecurity Scale; RCSI: Reduced coping strategy index; FCS: Food consumption score; SAFS: Self-assessed measure of food security; ANOVA: Analysis of variance; US\$: US Dollar; ZAR: South African Rand; LBPL: Lower-bound poverty line; UBPL: Upper-bound poverty line; Stats SA: Statistics South Africa.

\section{Authors' contributions}

BM collected and captured the data; CN and WOT analysed and interpreted the data, and both contributed to writing the manuscript. All authors read and approved the final manuscript.

\section{Authors' information}

Professor Carin Napier is an Associate Professor in the Department of Food and Nutrition at the Durban University of Technology in South Africa (SA). She started her work career as a food service manager in community hospitals. Working in communities, and dealing with food and nutrition issues, convinced her to pursue a career in this field of nutrition. Working at an academic institution for the last 18 years has given her the ideal opportunity to practice food and nutrition in the context of educating students, doing research as well as uplifting communities served by the University she worked in. She has successfully supervised 23 Masters and 2 PhD students and is currently supervising 16 Masters and $4 \mathrm{PhD}$ students. She has published 23 articles in accredited journals and presented papers at numerous international and national conferences. She is a registered Nutritionist with the Health Professions Council of South Africa. Her beliefs are that Nutritionists affiliated with academic institutions can impact on the nutritional health of the communities that they serve and sharing this information through publications and presenting it to policy makers. Planned interventions through postgraduate and independent studies can impact on the nutritional health of the communities. Her field of research is in line with national and international policies. Food and Nutrition security research can contribute towards achieving the Sustainable Development Goals, the SA National Development Plan, Food and Nutrition Security policy as well as the Integrated Nutrition Programme of the South African Department of Health. Dr. Wilna Oldewage-Theron is a Professor of Nutrition in the College of Human Sciences at Texas Tech University. She has eighteen years Community Nutrition research experience in Africa and is a National Research Foundation (NRF)-rated researcher in South Africa (SA). Her research interests include the factors contributing to household food insecurity and malnutrition in resource-poor communities where she has investigated the effect of various interventions, such as food fortification, supplementation, nutrition education, food product development and implementation, as well as school feeding programs on food insecurity, dietary diversity and nutritional status of women and children as well as the elderly. Her community research and development programme at present is mainly focused on the double burden of disease (micronutrient deficiencies and lifestyle diseases) as well as soy applications and the nutritional benefits of soy for human health in SA. She has also been involved in impact studies for the Council for Scientific and Industrial Research (SA), Joint Aid Management, the US Potato Board, and the World Initiative for Soy in Human Health (USA). Mrs Beryl Mbalenhle Makhaye was a postgraduate student in the Department of Food and Nutrition Consumer Science at the Durban University at the time of the study; she studied towards her Masters of Applied Science in Food and Nutrition. She collected the data in the refugee community in the Durban City Centre. She is an entrepreneur and manages her own business.

\section{Author details}

${ }^{1}$ Department of Food and Nutrition Consumer Sciences, Durban University of Technology, P. O. Box 1334, Durban 4000, South Africa. ${ }^{2}$ Department of Nutritional Sciences, College of Human Sciences, Texas Tech University, P. O. Box 41270, Lubbock, TX 79409-1270, USA.

\section{Acknowledgements}

The authors would like to thank the Kwazulu-Natal Refugee Council, the participants and the fieldworkers who assisted with data collection. Sanjoy Saha at Texas Tech University assisted with the statistical analyses.

\section{Competing interests}

The authors declare that they have no competing interests.

\section{Availability of data and materials}

The dataset used and/or analysed during the current study is available from the corresponding author or reasonable request.

\section{Consent for publication}

Not applicable.

\section{Ethics approval and consent to participate}

The Institutional Research Ethics Committee of Durban University of Technology (DUT) (REC38/13) approved the study. Permission was obtained from the Pastor's Network to consult with the women before or after their weekly prayer meetings within their premises. The Refugee Social Services was also approached for permission to meet asylum seekers/refugees in their orientation room, after their orientation sessions on Mondays from 08h30. All the women consented to participate.

\section{Funding}

No funding was received towards this study.

\section{Publisher's Note}

Springer Nature remains neutral with regard to jurisdictional claims in published maps and institutional affiliations.

Received: 27 July 2018 Accepted: 20 September 2018

Published online: 25 September 2018

\section{References}

1. African Centre for Migration and Society (ACMS), University of Johannesburg. 2006. African Cities Study 2006. http://www.migration.org.za/proje cts. Accessed 03 Oct 2016.

2. Baiphethi MN, Jacobs PT. The contribution of subsistence farming to food security in South Africa. Agrekon. 2009;48(4):459-82.

3. Bhattacharya J, Currie J, Haider S. Poverty, food insecurity and nutritional outcomes in children and adults. J Health Econ. 2004;23(4):839-62.

4. Caraher M. Food policy and regeneration: food for thought. Local Work: Voice. Centre Local Econ Strateg. 2005;64:1-4.

5. Dharod JM, Croom J, Sady CG, Morrell D. Dietary intake, food security, and acculturation among Somali refugees in the United States: results of a pilot study. J Immigr Refug Stud. 2011;9(1):82-97.

6. Dharod JM, Croom JE, Sady CG. Food insecurity: its relationship to dietary intake and body weight among Somali refugee women in the United States. J Nutr Educ Behav. 2013;45(1):47-53.

7. Dibsdall LA, Lambert N, Frewer LJ. Using interpretative phenomenology to understand the food-related experiences and beliefs of a select group of low-income UK women. J Nutr Educ Behav. 2002;34(6):298-309.

8. Dibsdall LA, Lambert N, Bobbin RF, Frewer LJ. Low-income consumers' attitudes and behaviour towards access, availability and motivation to eat fruit and vegetables. Public Health Nutr. 2003;6(02):159-68.

9. Fanzo J. Strengthening the engagement of food and health systems to improve nutrition security: synthesis and overview of approaches to address malnutrition. Global Food Secur. 2014;3(3):183-92.

10. Gladden J. Coping strategies of Sudanese refugee women in Kakuma Refugee Camp, Kenya. Refug Surv Q. 2013;32(4):66-89.

11. Hadley C, Sellen D. Food security and child hunger among recently resettled Liberian refugees and asylum seekers: a pilot study. J Immigr Minor Health. 2006;8(4):369-75.

12. Hadley C, Zodhiates A, Sellen DW. Acculturation, economics and food insecurity among refugees resettled in the USA: a case study of West African refugees. Public Health Nutr. 2007;10(04):405-12.

13. Labadarios D, Mchiza ZJR, Steyn NP, Gericke G, Maunder EMW, Davids YD, Parker WA. Food security in South Africa: a review of national surveys. Bull World Health Organ. 2011;89(12):891-9.

14. Maharaj V, Tomita A, Thela L, Mhlongo M, Burns JK. Food insecurity and risk of depression among refugees and immigrants in South Africa. J Immigr Minor Health. 2016;19:1-7.

15. Maxwell D, Ahiadeke C, Levin C, Armar-Klemesu M, Zakariah S, Lamptey GM. Alternative food-security indicators: revisiting the frequency and severity of coping strategies. Food Policy. 1999;24(4):411-29. 
16. Maxwell D, Watkins B, Wheeler R, Collins G. 2003. The coping strategies index: A tool for rapidly measuring food security and the impact of food aid programs in emergencies. Nairobi: CARE Eastern and Central Africa Regional Management Unit and the World Food Programme Vulnerability Assessment and Mapping Unit. http://www.fao.org/3/a-ae513e.pdf. Accessed 20 Mar 2017.

17. Maxwell D, Vaitla B, Coates J. How do indicators of household food insecurity measure up? An empirical comparison from Ethiopia. Food Policy. 2014:47:107-16

18. Napier C. 2006. Evaluation of a feeding programme in addressing malnutrition in a primary school. DTech thesis. Vaal University of Technology.

19. Ngidi MS, Hendriks SL. Coping with food insecurity in rural South Africa: the case of Jozini, KwaZulu-Natal. Mediterr J Soc Sci. 2014;5(25):278-89.

20. Radimer CL, Olson CM, Greene JC, Campbell CC, Habicht JP. Understanding hunger and developing indicators to assess it in women and children. J Nutr Educ. 1992;24(suppl 1):36S-44S.

21. Seligman HK, Laraia BA, Kushel MB. Food insecurity is associated with chronic disease among low-income NHANES participants. J Nutr. 2009;140(2):304-10.

22. Shariff ZM, Khor GL. Household food insecurity and coping strategies in a poor rural community in Malaysia. Nutr Res Pract. 2008;2(1):26-34.

23. Shisana O, Labadarios D, Rehle T, Simbayi L, Zuma K. South African National Health and Nutrition Examination Survey (SANHANES-1). Cape Town: HSRC Press; 2013. p. 135-44.
24. Statistics South Africa (StatsSA). (2015). Methodological report on rebasing of national poverty lines and development of pilot provincial poverty lines. Technical report 03-10-11. Pretoria: Statistics South Africa.

25. The World Bank. 2016. Poverty \& Equity Data. http://povertydata.world bank.org/poverty/home. Accessed 08 Dec 2016.

26. Townsend MS, Peerson J, Love B, Achterberg C, Murphy SP. Food insecurity is positively related to overweight in women. J Nutr. 2001;131(6):1738-45.

27. United Nations Refugee Agency (UNHCR). (2011). Global report 2011. http://www.unhcr.org/gr11/index.xml. Accessed 01 Mar 2017.

28. United Nations Refugee Agency (UNHCR). (2012). South Africa. http:// www.unhcr.org/51b1d637b.html. Accessed 01 Mar 2017.

29. United Nations Refugee Agency (UNHCR). (2015). UNHCR Statistics. The world in numbers. http://popstats.unhcr.org/en/overview\#_ga=1.30122 495.1963645507.1481038969. Accessed 01 March 2017.

30. Vozoris NT, Tarasuk VS. Household food insufficiency is associated with poorer health. J Nutr. 2003;133(1):120-6.

31. Vhurumuku, E. 2014. Food security indicators. http://www.fao.org/filea dmin/user_upload/food-security-capacity-building/docs/Nutrition/Nairo biWorkshop/5.WFP_IndicatorsFSandNutIntegration.pdf. Accessed 15 Sep 2017
Ready to submit your research? Choose BMC and benefit from:

- fast, convenient online submission

- thorough peer review by experienced researchers in your field

- rapid publication on acceptance

- support for research data, including large and complex data types

- gold Open Access which fosters wider collaboration and increased citations

- maximum visibility for your research: over $100 \mathrm{M}$ website views per year

At BMC, research is always in progress.

Learn more biomedcentral.com/submissions 